\title{
Light rail transit in Mysore: complimenting land use and transport
}

\author{
G. Ghosh \\ Sky Group, India
}

\begin{abstract}
Most Indian cities are low-rise urban trails and require medium capacity modes only. As per the recommendations of the working group on urban transport for the 12th FYP (Five Years' Planning), light rail transit (LRT) should be provided in all cities with a population of million plus. The Comprehensive Mobility Plan of Mysore highlights LRT as one of the option of mass transit mode to change the travel characteristics from a primarily private mode based to a mass transport based. The goal of the project is to analyse the role of LRT in the existing transportation system and existing land use pattern in Mysore. On account of ideal travel demand, engineering and land use compatibility, LRT emerges as a feasible mode of travel in Mysore.

Keywords: role of light rail transit, medium sized cities, India, Mysore, mass rapid transit.
\end{abstract}

\section{Background}

Cities in India have been growing at a rapid pace. $32 \%$ of the Indian population stay in cities today which are pained by severe crunches in infrastructure and utilities. Transport and connectivity are one of the basic requirements of any city and the rapid urbanisation in India calls for mass rapid transit. Initiatives have been taken in several cities to introduce mass transport and some of them have been reasonably successful. New Delhi, the capital of India, has the longest metro rail network in India and it has helped address the transport problem in the city. Other metro cities like Kolkata and Bangalore are also using metro rail as a solution to the transport problem. This paper tries to examine the role of light rail transit in medium sized Indian cities. LRT, though has been reasonably successful in European cities, its potential and role in Indian cities have been 
largely down played till now citing low carrying capacities compared to Metro rail and higher costs than the bus rapid transit system [1]. LRT is known to have high land use potential in environments where policies are pro-development. Light rail also continues to be implemented in progressively smaller cities than previously noted with cities having populations as low as 150,000 choosing to make significant long-term capital investments in fixed rail facilities [3]. Recently, the Government of India has made statements to examine the feasibility of light rail transit in Indian cities. It is in context of such initiatives that the present study has been conceived in the city of Mysore in the state of Karnataka. The goal of the project is to analyse the role of LRT in the existing transportation system and existing land use pattern in Mysore.

\section{Previous research}

Light rail transit is a metropolitan electric railway system characterized by its ability to operate single cars or short trains along exclusive rights-of-way at ground level, on aerial structures, in subways or, occasionally, in streets, and to board and discharge passengers at track or car-floor level (Transport Research Board, 1978). Light rail is a form of rail-based transport that is particularly suited to distances between 10 and $40 \mathrm{~km} \mathrm{[2].} \mathrm{There} \mathrm{has} \mathrm{been} \mathrm{deep} \mathrm{criticism} \mathrm{about} \mathrm{the}$ merits of light rail. This criticism follows two broad lines: first, the decisionmaking on light rail has been characterized as biased and irrational and the second, the merits of light rail as compared to bus based systems has been contested. The essence of light rail is that it is a hybrid form of transport. It involves passenger rail transport vehicle as regards size and weight, stands between hybrid form of urban tram and a conventional train. Due to this hybrid character light rail can adopt characteristics of heavy rail, urban tram as well as subway models. These include operating speed and stop distances can be adopted as per requirement [3].

Research in the context of Indian conditions has been relatively scarce compared to the international arena. Rathod (cited in [4]) has studied on the feasibility of a light rail transit system: a case study of a section from APMC (Agricultural Produce Market Committee) to RTO (Road Transport Organisation) in Ahmedabad. Ahmedabad metropolitan has a population of $6,352,254$. Boral has studied the topic of tramway an eco-friendly mode of mass transportation: a case of Kolkata city (in [4]). The principal function of any transit system is to carry passengers efficiently and in large numbers. Tramcars stand out in comparison to other vehicular modes within the transport system of Kolkata for its distinctiveness. A white paper by FCCI (the Federation of Indian Chambers of Commerce and Industry) on light rail transit in India establishes the feasibility of the transport mode in Indian cities [5].

\section{Research methodology}

As per the recommendations of the working group on urban transport for the 12th FYP (Five Year Plan), LRT should be provided in all cities with a 
population of a million plus. There are 53 cities in this category as per the 2011 census. Thus all these cities are couriers for introduction of LRT. Mysore is one of the two urban agglomerations in Karnataka that are in the million population range. The Comprehensive Mobility Plan of Mysore highlights LRT as one of the option of mass transit mode to change the travel characteristics from a primarily private mode based to a mass transport based. Hence Mysore presented an interesting choice of a study location due to its inherent tourist centric and institutional character.

The study had the following aims:

- To understand whether there is an established demand corridor in the city.

- To understand whether the operating and engineering characteristics of LRT would be feasible in the city.

The study comprised collecting primary data on classified traffic volume counts on major roads, O-D (origin-destination) surveys and road inventory. Secondary data was studied from the transport model from CMP report related to the trip generation and zones and destination zones. Parallelly the existing and proposed land use and activity pattern was studied from the city development plan and Master plan. The resultant outputs were aligned towards identifying demand corridors for mass transport, engineering and land use feasibility for LRT. The results were used to propose LRT on two routes in the city.

\section{Study area}

The city of Mysore is a national tourist attraction known for its palaces and royal heritage. The Mysore urban agglomeration houses a population of close to 1 million. It is administered by the Mysore Municipal Corporation for a geographical extent of $128 \mathrm{sqkm}$. The city is well connected to adjoining states through state highways and national highways. The palace is the focal point of the city from where all arterial roads radiate towards surrounding towns and cities. It has a global tourism catchment resulting in 13.4 lakh tourists annually. The morphology of the city has a radial nature. The core city of Mysore consists of the Mysore palace and its surrounds. The core comprises of the old dense commercial areas, railway and bus terminals, secretariat and government offices and educational institutions. The second ring around the core consists of residential clusters, the Mysore University campus, educational institutions and Mysore zoo and other tourist attractions. The third ring abutting the outer ring road consists of clusters of manufacturing and information technology (IT) industries and upcoming residential areas. The character of the inner city is essentially defined by the palace and its surrounding, acquiring a heritage nature while that of the outer areas by more modern development as seen in the map below (see fig. 1). 


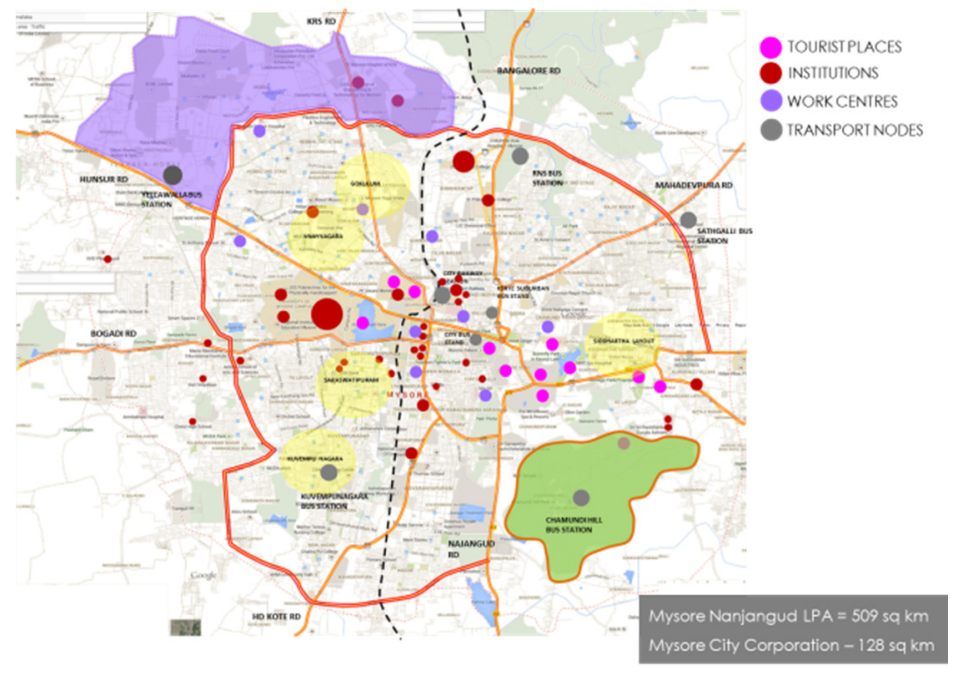

Figure 1: Study area.

\section{$5 \quad$ Traffic and travel characteristics}

\subsection{Road network characteristics}

The city of Mysore is served by a well-established grid network. It is essentially grid based with arterial roads radiating from the city centre. The total road network amounts to $1170 \mathrm{~km}$. the city is connected to nearby towns and cities via national and state highways. The city is also served by the national railway network. Almost all roads are of good quality with a right of way (RoW) of $18 \mathrm{~m}$ to $30 \mathrm{~m}$. Table 1 presents an inventory of roads in the city.

The city bus system forms the mode of public transport in the city which has a high spatial coverage. The map below shows the transportation network and facilities in Mysore (see fig. 2).

\subsection{Traffic survey inferences}

A comprehensive mobility plan was conducted for Mysore in 2011. The data set of traffic and travel survey has been appended with some data from that report. Classified volume counts were carried out in the following locations to accumulate the following data.

1. Average daily traffic (ADT);

2. Hourly variation and peak hour flows;

3. Directional distribution by hour of the day;

4. Traffic composition.

The traffic survey was carried out continuously for 24 hours for 7 days at mid-block locations, while the survey at Screen Line and Outer Cordon locations 
Table 1: $\quad$ Road network inventory of roads in Mysore.

\begin{tabular}{|l|l|l|}
\hline SL & NAME OF ROAD & RoW $(\mathrm{m})$ \\
\hline 1 & Mahatma Gandhi Road & 24 \\
\hline 2 & Ashoka Road & 20 \\
\hline 3 & Church Road & 24 \\
\hline 4 & Nilgiri Road & 30 \\
\hline 5 & Mysore University Road & 30 \\
\hline 6 & Bangalore Road & 36 \\
\hline 7 & T. Narsipura Road & 36 \\
\hline 8 & H D Kote Road & 24 \\
\hline 9 & Mahadevpura Road & 24 \\
\hline 10 & Kalidasa Road & 20 \\
\hline 11 & Ramvilas Road & 24 \\
\hline 12 & Chamaraja double road & 30 \\
\hline 13 & JLB Road & 30 \\
\hline 14 & Hunsur Road & 36 \\
\hline 15 & Vinoba Road & 30 \\
\hline
\end{tabular}

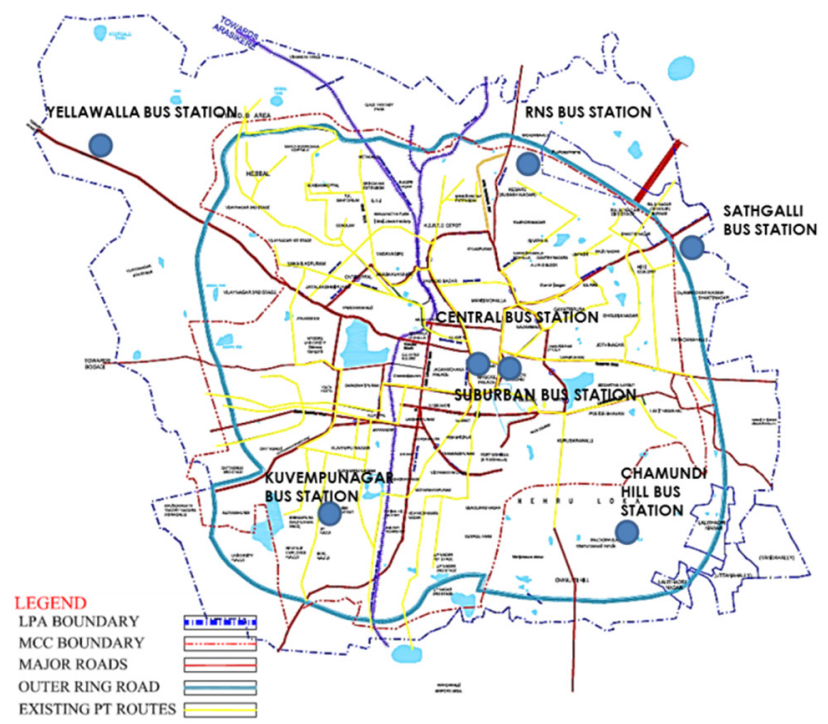

Figure 2: Transport network characteristics in Mysore.

were conducted for 16 hours for 3 days. The locations of the major road were accounted for in the selection of the survey sites in order to ensure maximum capture of traffic. The counts were carried out in both directions. It is observed that the traffic volume is as high as 73,444 PCU. From analysed data it is 
observed that the intensity of a 2-wheeler is predominant in most of the roads with the composition varying between $19 \%$ and $50 \%$ while that of cars is $17 \%$ to $35 \%$. Total PHPDT (peak hour peak direction trip) on major roads range 12,000 to 15,000 trips.

Classified volume counts at the outer cordon locations were conducted to gauge the traffic characteristics at the various access points pertaining to the study area. From the analysis it is observed that the volume of traffic is highest towards Bangalore Road.

\subsection{Traffic model inferences}

Survey results of trips made by individual household member were collected to get the actual trip pattern in the city. The 65 wards of the Mysore City Corporation were considered as traffic zones. An analysis of trip by purpose and trip length indicates that maximum number of trips are performed within $5 \mathrm{~km}-$ $10 \mathrm{~km}$ distance and average trip length is $7.8 \mathrm{~km}$. Maximum no of trips are made by 2 -wheelers, followed by buses including mini (private) tourist buses.

The major trip producing zones were found in the north-west, south-west and south east of the city. The zones confirm with the land use pattern of Mysore.

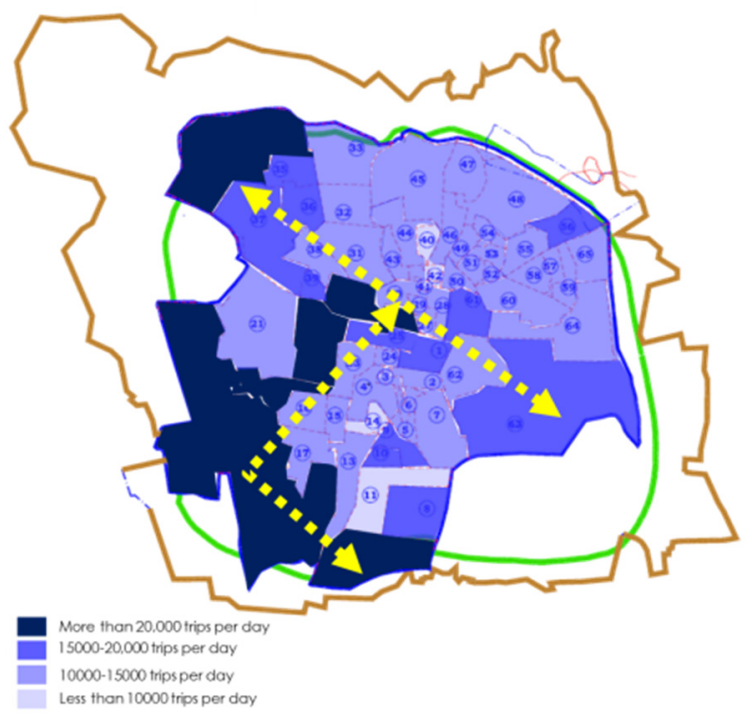

Figure 3: Trip attraction zones. 


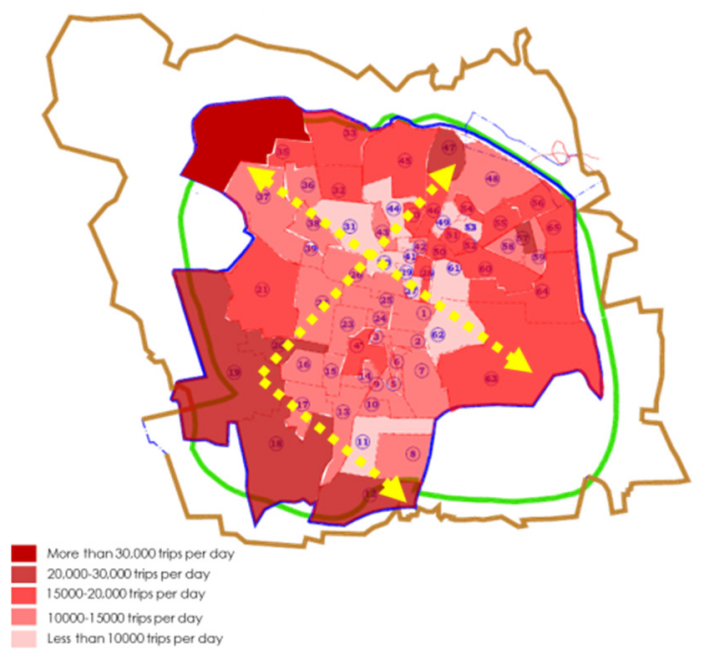

Figure 4: Trip production zones.

The north-west zone of IT (information technology) hub, south-west zone of major residential areas, south-west zone of major residential areas, south-east zone of tourist attractions. The desire diagram derived from the transport model as seen in fig. 5. Major travel corridors can be derived from this. It also shows that the traffic in Mysore has huge externalities owing to the volume of regional traffic inflow into the city. Hence it can be inferred that without any major change in the economic geography of the region the travel corridors would remain constant.

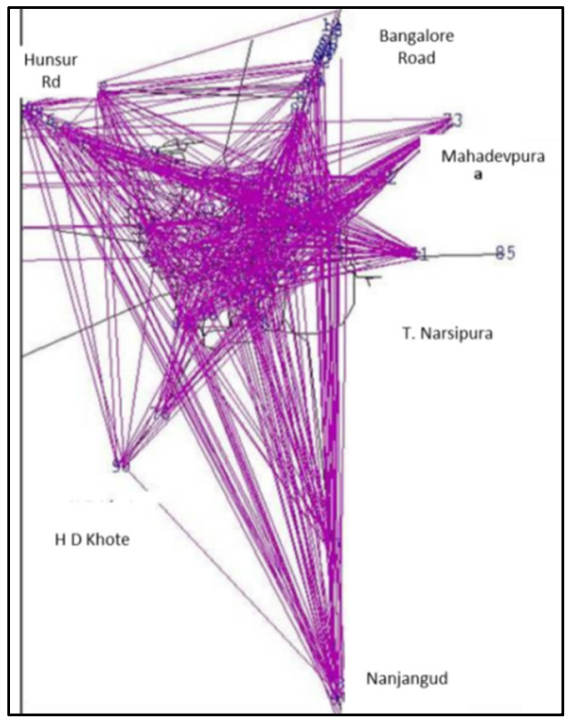

Figure 5: Travel desire line diagram in Mysore. 


\section{Identification of potential LRT routes}

The existence of a definite demand corridor and high peak hour trips of 12,000 to 15,000 trips present a distinct opportunity for alignment of light rail. On the identified corridor route was identified to connect the major nodes to obtain the highest ridership. The first route was identified along the north-west to the south-east of the city passing through the core, called the Palace line. The route connects the industrial cluster, the Mysore University, the city railway station and the bus station, the Mysore palace and the tourist cluster in the south-east. It would serve intercity passengers moving from the city core toward the north, north-west, comprising of the work trips in the city. It would also serve intercity tourists travelling south from the city bus station and the railway station. The operational characteristics of LRT suit the institutional and tourist character of the city. It provides connection between origin and destination zones of trips and would generate a daily ridership of 6 lakhs. It is assumed to have a shift of $15 \%$ from other modes, mostly 2-wheelers, cars and private tourist vehicles. Ridership of existing public transport system is not expected to reduce by not more than $2 \%$.

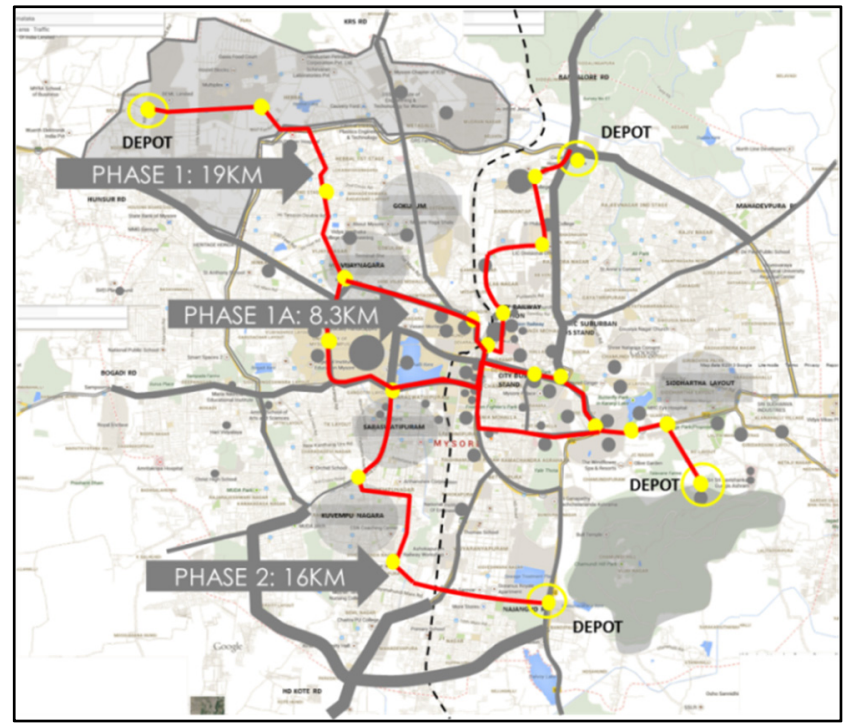

Figure 6: Potential alignment of light rail in Mysore.

The second route is identified along the north-south axis from the northern end of the Mysore conurbation, till the southern end of the conurbation, called the North-South line. This route is designed to capture the regional traffic entering and leaving the city which forms $26 \%$ of the daily traffic volume. The route would serve to decongest the city core by restricting regional traffic to 
the outskirts of the city. The route would generate a daily ridership of 8lakh passengers. The routes are expected to decongest the city by making a modal shift from 2-wheelers and private modes.

\section{Technology assessment}

Initial technology assessment has been carried out according to feasibility in Mysore. Light Rail Transit is a medium capacity rapid transport mode that runs on designated or shared pathway. Vehicles are in the form of articulated trams or LRT vehicles that serve a typical ridership of 10000 to 20000 passengers within urban areas. Speed ranges from $20 \mathrm{kmph}$ on arterial roads and $15-17 \mathrm{kmph}$ on dense urban roads $[6,7]$. At grade system has been proposed as ample RoW is available in the city. Articulated vehicles were found suitable for roads of Mysore as turning radius available is low [8]. Low floor vehicles with low height stops have been proposed for universal accessibility. Single ended operation can be used as ample space is available for end loop. Street and block paved pathway with shared track is advised in response to limited RoW in certain sections of the road network. Central stops have been found feasible in most of the roads (as seen in figs 7 and 8). Staggered platforms may be designed in sections of a narrower right of way.
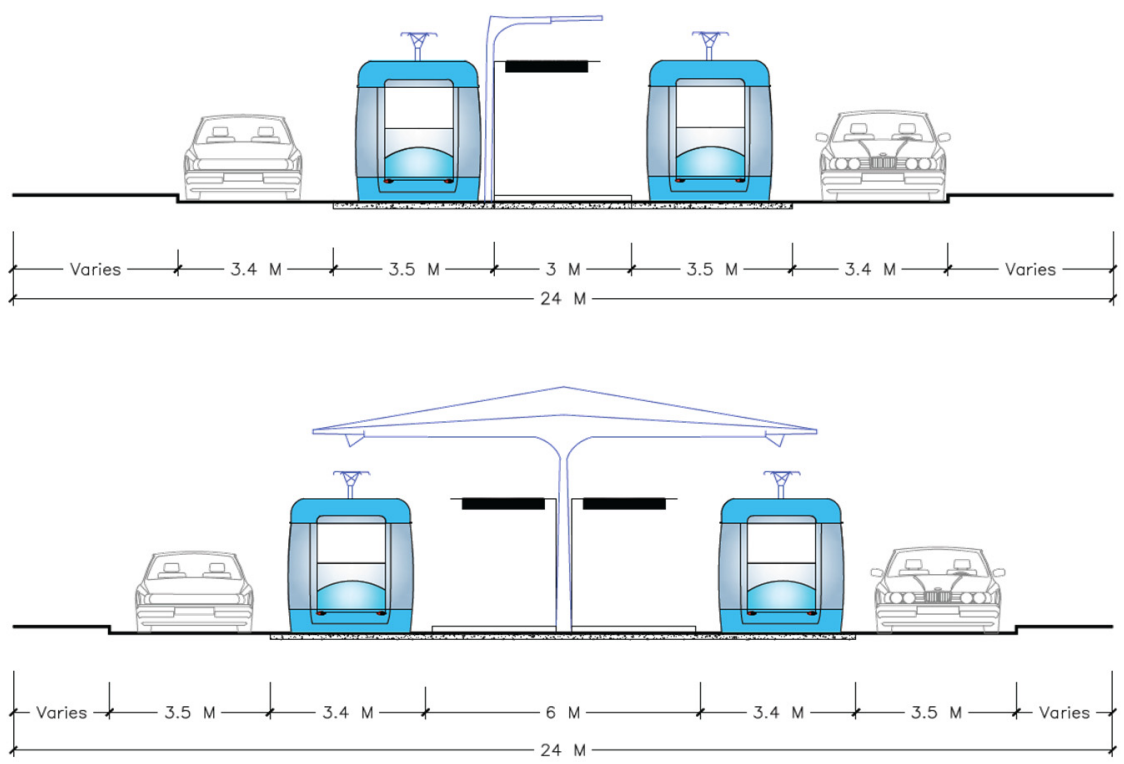

Figure 7: Mid-block and station area intersection on $24 \mathrm{~m}$ RoW roads. 

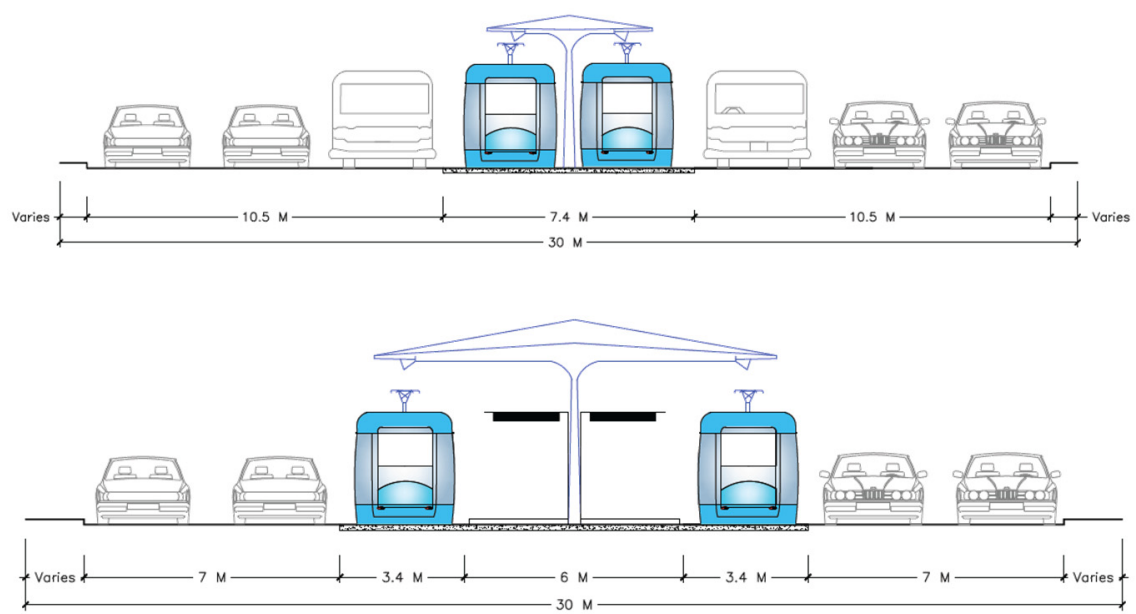

Figure 8: Mid-block and station area intersection on $30 \mathrm{~m}$ RoW roads.

\section{Conclusion}

The results of the study strongly indicate that LRT can be used as a mass transport mode in Mysore. The study of passenger trips along the major corridors provides a sustainable demand for LRT transit in the base year and is progressively anticipated to increase in the future. The tourist and institutional district in Mysore also benefits from the urban image conferred by Light rail. The flexibility of the light rail of mixing with traffic on city streets, while also achieving relatively high speeds and cleaner environmental impacts provides opportunity in Indian cities. LRT helps in decongesting the city without depriving the other modes of their right of road space. It ideally integrates land use and transportation in the city.

Light rail transit is a new concept in India. Most of the research has been concentrated on metro rail and bus rapid transit though metro is suitable only when traffic volumes are as high as 70,000-90,000 PHPDT and BRT (bus rapid transit) is successful only with segregated right of way for the entire network [9]. Both these characteristics are difficult to satisfy in medium sized Indian cities. LRT provides a more feasible mode in between Metro rail and BRT in terms of ridership as well as cost. The study makes an attempt to showcase how LRT can be seamless integrated into the existing land use and transport of the city.

\section{References}

[1] Cervero Robert, Journal Report: Light Rail Transit and Urban Development, pp. 133-147 (published online 2007). 
[2] Peter Topalovic, Leslea Lottimer, Mary-Kaye Pepito, Light Rail Technology-Overview \& Analysis, 2009.

[3] David B. McBrayer, Blurring the Light Rail Transit-Bus Rapid Transit Boundaries: Rapid Light Transit, 9th National Light Rail Transit Conference 2003.

[4] Sanghvi Dhruv, Varia H. R., Light Rail Transit - Today's Need for Developing Cities in India, International Journal of Science and Research (IJSR) ISSN (online): 2319-7064, 2015.

[5] Modern Trams (light rail transit) for Cities in India, FICCI \& Institute of Urban Transport (India), Sept 2013.

[6] Transportation Research Circular E-C058: 9th National Light Rail Transit Conference 2003.

[7] Donna L. Day, Susan A. Stauder, Planning and Forecasting for Light Rail Transit, 9th National Light Rail Transit Conference 2003.

[8] Marc le Tourneur, The Tramway, aka LRT - An efficient, aesthetic, durable mass transport resource for medium-sized Indian cities, Urban Mobility Conference, 2010.

[9] Hiroya Fujimoto, The Modal Shift to Environmentally Sustainable Transport: Prospects of Urban Transport Systems: LRT, BRT and Buses; Science \& Technology Trends, Quarterly Review no. 28, 2008. 